\title{
ANALISIS EFEKTIVITAS PROGRAM KELUARGA HARAPAN DALAM PENGENTASAN KEMISKINAN DI DESA SUMBER HARAPAN DUSUN SOLOR MEDAN
}

\author{
Ahmad Yasir \\ Institut Agama Islam Sultan Muhammad Syafiuddin Sambas \\ Corresponding Author: e-mail: yasirahmad200981@gmail.com \\ U. Sulia Sukmawati \\ Institut Agama Islam Sultan Muhammad Syafiuddin Sambas \\ e-mail: urai_suliasukmawati@yahoo.com \\ Iva Ashari Ananda \\ Institut Agama Islam Sultan Muhammad Syafiuddin Sambas \\ e-mail: ivaashariananda@gmail.com \\ Karisma \\ Institut Agama Islam Sultan Muhammad Syafiuddin Sambas \\ e-mail: ismirisma@gmail.com
}

\begin{abstract}
Program Keluarga Harapan or known as $\mathrm{PKH}$ is social assistance and protection, including cluster I of poverty reduction strategies related to education, health, and basic fulfillment for the elderly and people with severe disabilities. The research aims to determine the effectiveness of Program Keluarga Harapan in alleviating poverty, changing people's welfare and to provide information and evaluation to the government, how effective and targeted it is for people who receive assistance. This research uses a qualitative method based on the philosophy of positivism, namely qualitative research with quantitative data using interview techniques and questionnaires. This research applied saturated sample consisting of 37 $\mathrm{PKH}$ participants. In analyzing the data, this research applied descriptive analysis of the collected data. The effectiveness is measured using three indicators, namely input, process and output. Of the three indicators, the level of effectiveness in Sumber Harapan Village, at Solor Medan Sub Village is very effective. In terms of welfare, people who receive $\mathrm{PKH}$ based on BKKBN standards are also considered prosperous families.
\end{abstract}

Keywords: effectiveness, $\mathrm{PKH}$, prosperity

\begin{abstract}
ABSTRAK
Program Keluarga Harapan atau yang dikenal dengan PKH merupakan bantuan dan perlindungan sosial termasuk klaster I strategi penanggulangan kemiskinan berkaitan dengan pendidikan, kesehatan, dan pemenuhan dasar bagi lanjut usia dan penyandang disabilitas berat. Penelitian betujuan untuk mengetahui tingkat efektivitas Program Keluarga Harapan dalam pengentasan kemiskinan, perubahan kesejahteraan
\end{abstract}


masyarakat serta memberikan informasi dan evaluasi kepada pemerintah, seberapa efektif dan tepat sasaran bagi masyarakat yang mendapatkan bantuan. Peneltian ini menggunakan metode kualitatif yang berlandaskan pada filsafat positivisme yaitu penelitian kualitatif dengan data kuantitatif menggunakan teknik wawancara dan penyebaran angket. Peneliti menggunakan sampel jenuh yang terdiri dari 37 peserta PKH. Dalam menganalisis data, penulis menggunakan analisis deskriptif dari data-data yang telah dikumpulkan. Efektivitas yang diukur menggunakan tiga indikator yaitu input, proses dan output. Dari ketiga indikator tersebut tingkat efektivitas di Desa Semberang Dusun Solor Medan sangat efektif. Dari sisi kesejahteraan masyarakat yang menerima PKH yang berdasarkan standar BKKBN juga sudah termasuk kedalam keluarga sejahtera.

Kata Kunci: Efektivitas, PKH, Kesejahteraan

\section{PENDAHULUAN}

Isu kemiskinan merupakan masalah kronis melanda Indonesia yang sangat berpotensi menghambat pembangunan ekonomi sebagai proses alami untuk mewujudkan cita-cita yang diamanatkan kepada negara yaitu masyarakat makmur sejahtera, adil, dan merata (Euis Amalia, 2009). Berdasarkan data yang diakses dari Badan Pusat Statistik, "Jumlah Penduduk Indonesia" (http://www.bps.go.id) menyatakan Indonesia negara yang memiliki penduduk terbesar ke empat di dunia, memiliki jumlah penduduk sekitar 260 juta jiwa terdiri dari 17.508 pulau dengan jumlah 34 provinsi dibagi menjadi 403 Kota dan 98 kota. Dengan populasi penduduk sebesar ini, membuat Indonesia memiliki banyak sekali persoalan rumit yang terjadi di masyarakat dengan jumlah penduduk miskin yang sangat banyak.

Pada lima tahun terakhir, jumlah penduduk miskin di Indonesia mengalami penurunan baik di perkotaan atau pun diperdesaan. Badan Pusat Statistika (BPS) mengumumkan jumlah penduduk miskin Indonesia per Maret 2019 sebanyak 25,14 juta jiwa atau 9,41\% dari total 260 juta penduduk Indonesia. Jumlah penduduk miskin berkurang 529,9 ribu orang dibandingkan Maret 2018, penurunanya mencapai 805,1 orang. Menurut Budi Raharjo yang di akses dari https://cnnindonesia.com berdasarkan pernyataan kepala BPS Suhariyanto, presentasi tingkat kemiskinan sudah berada dalam rentang satu digit yang mana masyarakat Indonesia yang kini hidup di bawah garis kemiskinan merupakan kelompok yang benar-benar berada pada posisi paling bawah.

Untuk menekan laju pertambahan penduduk miskin, pemerintah meningkatkan efektivitas penanggulangan kemiskinan melalui program pengentasan kemiskinan. Beberapa program seperti berbasis perlindungan sosial JAMKESMAS (Jaminan Kesehatan Masyarakat), RASKIN (Beras Miskin), BSM (Bantuan Siswa Miskin), PKH (Program Keluarga Harapan), PNPM (Program Berbasis Pemberdayaan Masyarakat), KUR (Pemberdayaan Usaha Mikro), program-program ini berdasarkan pasal 1 ayat (9) UU No.11 Tahun 2009 tentang kesejahteraan sosial menentukan bahwa: "perlindungan sosial adalah semua upaya yang diarahkan untuk mencegah 
dan menangani resiko dari guncangan dan kerentanan sosial" yang di akses pada laman kemnsos (https//www.kemsos.go.id/unduh/UU-kesosNo112009.pdf)

PKH tidak sama dengan bantuan langsung tunai (BLT) sebelumnya dan bukan merupakan program lanjutan dari program-program sebelumnya yang membantu mempertahankan daya beli rumah tangga miskin pada saat pemerintah melakukan penyesuaian harga bahan bakar minyak. PKH lebih dimaksudkan sebagai upaya membangun sistem perlindungan sosial kepada masyarakat miskin dalam rangka meningkatkan kesejahteraan sosial penduduk miskin sekaligus memutus rantai kemiskinan. PKH merupakan program bantuan dan perlindungan sosial yang termasuk dalam klaster I (kelompok kebijakan penanggulangan kemiskinana berbasis bantuan dan perlindungan sosial, strategi penanggulangan kemiskinan di Indonesia.

Program ini merupakan bantuan tunai bersyarat yang berkaitan dengan persyaratan pendidikan dan kesehatan (Tim Nasional Percepatan Penanggulangan Kemiskinan, 2012:19). Tujuan diberlakukannya PKH dalam jangka panjang adalah untuk memutus mata rantai kemiskinan, meningkatkan kualitas sumber daya manusia, serta merubah prilaku RTM yang relatif kurang mendukung peningkatan kesejahtraan dari kelompok miskin.

Tabel 1

Perubahan Jumlah Penduduk Miskin di Kabupaten Sambas Periode 2014-2018

\begin{tabular}{|c|c|c|c|}
\hline Tahun & $\begin{array}{c}\text { Garis Kemiskinan } \\
\text { Rupiah }\end{array}$ & Po (\%) & $\begin{array}{c}\text { Jumlah Penduduk } \\
\text { Miskin (000) }\end{array}$ \\
\hline 2014 & 314144 & 9,46 & 49,26 \\
\hline 2015 & 329993 & 9,42 & 49,29 \\
\hline 2016 & 345066 & 8,54 & 44,88 \\
\hline 2017 & 369202 & 8,59 & 45,42 \\
\hline 2018 & 407346 & 8,55 & 45,48 \\
\hline
\end{tabular}

Sumber: BPS Tahun 2019

Berdasarkan tabel 1, jumlah kemiskinan mengalami fluktuatif. Tingginya kemiskinan di Kabupaten Sambas, maka diperlukan program penanggulangan kemiskinan. Banyak program yang sudah dijalankan oleh pemerintah diantaranya yaitu Program Harapan Keluarga (PKH). Kenaikan jumlah kemiskinan juga berpengaruh di kecamatan sambas dapat dilihat dari bertambahnya peserta penerima PKH di setiap desa. Jumlah keluarga miskin terbanyak berada di Desa Gapura diikuti Desa Kartiasa, Sei Rambah, Saing Rambi dan Desa Lumbang. Namun sebuah kewajaran karena ke-lima Desa itu memiliki jumlah penduduk yang sangat padat jika di bandingkan dengan desa lainnya. Tidak Terkecuali Desa Sumber 
Harapan yang menjadi tempat penilitian, jumlah kemiskinan sebanyak 175 Kepala Keluarga.

Tabel 2

Tabel Penerima Bantuan Program Keluarga Harapan Di Desa Sumber Harapan Tahun 2020

\begin{tabular}{|c|c|c|}
\hline No & Dusun & Jumlah \\
\hline 1 & Dusun Semberang 1 & 13 \\
\hline 2 & Dusun Semberang 2 & 31 \\
\hline 3 & Dusun Solor Medan & 37 \\
\hline & Total & 81 \\
\hline
\end{tabular}

Sumber : data dinas sosial kabupaten sambas 2020.

Data tabel 2, Desa Sumber Harapan terdiri dari tiga Dusun diantaranya Dusun Semberang I, Dusun Semberang II, dan Dususn Solor Medan. Jumlah penerima bantuan PKH, Desa Sumber Harapan adalah desa dengan jumlah terbanyak yang menerima bantuan PKH sebanyak 81 penerima dari 18 desa yang ada di Kecamatan Sambas Untuk peserta penerima. Wawancara dengan Ketua PKH Ibu Evi menyatakan, bantuan PKH di Desa Semberang dusun Solor Medan penerima Program Keluarga Harapan terbanyak dari tiga dusun tersebut oleh karena itu membuat peneliti tertarik melakukan penelitian yang mana Dusun Solor Medan ini terdapat 37 Kepala Keluarga yang mendapat PKH dari 81 Kepala Keluarga yang mendapat PKH.

Desa Sumber Harapan menjadi objek penelitian karena Desa Sumber Harapan termasuk bagian dari Kecamatan Sambas bertempat di ibu kota Kabupaten yang jarak tempuh dari desa Sumber Harapan ke kota tidak terlalu jauh. Selain itu Desa Semberang merupakan salah satu desa wisata tenun menjadi program pemerintah untuk meningkatkan pendapatan penduduk, dan masih banyak program bantuan lainnya dari pusat melalui BAZNAS yaitu program "Zakat Produktif" berupa bantuan modal usaha salah satunya untuk program wisata tenun bagi masyarakat tidak mampu.

Desa Sumber Harapan masih tergolong Desa Swasembada tingkat III, merupakan Desa yang sedang menuju Desa Mandiri. Menjadi sebuah tantangan dan harapan untuk Desa Semberang dalam mengefektivitaskan setiap program bantuan terutama program $\mathrm{PKH}$ untuk warga agar dapat mengurangi jumlah penduduk miskin. Dilihat dari manfaat Program Keluarga Harapan dalam mengurangi beban masyarakat miskin di Desa Sumber Harapan Dusun Solor Medan, hal inilah yang membuat ketertarikan peneliti untuk menganalisis efektivitas Program Keluarga Harapan (PKH) Dalam Pengentasan Kemiskinan Di Desa Sumber Harapan Dusun Solor Medan Kecamatan Sambas.

1. Konsep Efektivitas

Penilaian efektivitas suatu program perlu dilakukan untuk mengetahui sejauh mana dampak dan manfaat yang dihasilkan oleh program tersebut. Karena efektivitas merupakan gambaran keberhasilan 
dalam mencapai sasaran yang telah ditetapkan. Melalui penilaian efektivitas ini dapat menjadi pertimbangan mengenai kelanjutan program tersebut (Kartiawati, 2020:52)

\section{Ukuran Efektivitas}

Efektivitas yang akan dicapai dalam Program Keluarga Harapan (PKH) untuk menentukan apakah Program Kelurga Harapan (PKH) tersebut efektiv ataupun sebaliknya dapat dilihat dan dapat diukur. Sebagimana tingkat Efektivitas diukur dengan menggunakan standar sesuai dengan acuan Litbang Depdagri (1991) sebagaimana tabel berikut ini :

Tabel 3

Standar Ukuran Efektivitas Sesuai Acuan Litbang Depdagri

\begin{tabular}{|c|c|c|}
\hline No & Rasio Efektivitas & Tingkat Capaian \\
\hline 1 & Di bawah 40 & Sangat Tidak Efektif \\
\hline 2 & $40-59,99$ & Tidak Efektif \\
\hline 3 & $60-79,99$ & Cukup Efektif \\
\hline 4 & Diatas 80 & Sangat Efektif \\
\hline
\end{tabular}

Sumber: Jurnal Ekonomi dan Sosial INPUT

Efektivitas juga merupakan pencapaian tujuan organisasi melalui pemanfaatan sumberdaya yang dimiliki secara efisien, ditinjau dari sisi masukan (input), proses, maupun keluaran (output). Sehingga efektivitas program dapat dirumuskan sebagai tingkat perwujudan sasaran yang menunjukkan sejauh mana sasaran program yang telah ditetapkan, apakah memberikan hasil sesuai dengan yang menjadi tujuan progam atau tidak (Asti Parichati, 2019:19)

\section{Indikator Efektivitas $\mathrm{PKH}$}

Indikator merupakan hal yang dapat menentukan sebuah kegiatan yang akan dilakukan sebagimana dalam imdikator efektivitas $\mathrm{PKH}$ kegiatan memonitoring menjadi bagian dari kegiatan evaluasi operasional yang bertujuan untuk menilai efektivitas pelaksanaan program. Ruang lingkup pemanfaatan $\mathrm{PKH}$ secara umum dilakukan pada sisi input, proses dan output (Direktorat Jaminan Sosial Keluarga, 2019)

Setiap program yang dijalankan selalu ada evaluasi dari program yang bertujuan menilai efektifitas program yang sudah dijalankan. Setiap kegiatan akan efisien jika dikerjakan dengan benar sehingga menghasilkan hal yang bermanfaat. Dalam hal ini, efektivitas program merupakan sebagai perwujudan dan sajauh mana sasaran program yang telah dilaksanakan dapat memberikan hasil yang sesuai dengan tujuan program (Nih Ayu Kartika, 2017).

\section{METODE PENELITIAN}

Peneltian ini menggunakan metode kualitatif yang berlandaskan pada filsafat positivisme yaitu penelitian kualitatif dengan data kuantitatif. Teknik pengumpulan informan dengan sampel jenuh karena populasi 
semuanya dijadikan sampel. Peneliti melakukan sendiri dalam mewawancarai informan baik secara langsung (Sugiono, 2017:29). Dengan jumlah informan yang diwawancarai sebanyak 37 kepala keluarga.

Analisis data dalam penelitian dengan mendeskriptifkan, mengkategorisasi, mengkoneksi data penelitian. Langkah pertama dengan melakukan mendiskripsian informan, dengan memilih data yang penting dari informan, melalui teknik pengumpulan data yaitu wawancara dan penyebaran kuesioner berskala Bougman (ya atau tidak). Langkah kedua melakukan kategorisasi dengan rumus persentase

$$
\text { Efektivitas Program }=\frac{R}{T} \times 100 \%
$$

$\mathrm{R}=$ Jumlah Jawaban

$\mathrm{T}=$ Jumlah Total Jawaban

Efektivitas diukur dengan menggunakan standar sesuai dengan acuan Litbang Depdagri sebagaimana tabel berikut ini :

Tabel 4.

Standar Ukuran Efektivitas Sesuai Acuan Libang Depdagri

\begin{tabular}{|c|c|}
\hline Tingkat Efektifitas & Kategori \\
\hline$<40$ & Sangat Tidak Efektif \\
\hline $40-59,99$ & Tidak Efektif \\
\hline $60-79,99$ & Cukup Efektif \\
\hline$>80$ & Sangat Efektif \\
\hline
\end{tabular}

Sumber : Litbang Depdagri

Langkah terakhir connection dengan melakukan analisis yang mendalam terhadap data dan informasi yang diperoleh, sehingga menjadi suatu bangunan pengetahuan dan ilmu yang baru (Sugiono, 2017:29)

Sumber data merupakan subyek dari mana data-data penelitian bisa diperoleh Sumber data merupakan subjek dari mana data-data penelitian bisa diperoleh (Adnan Mahdi dan Mujahidin, 2014:123). Sumber data yang menjadi rujukan dalam penelitian ini yaitu:

a. Data Primer

Data yang diperoleh langsung dari responden atau obyek yang diteliti atau ada hubungannya dengan obyek yang diteliti, seperti hasil wawancara atau hasil pengisian kuesioner. Adapun informasi di wawancara terlebih dahulu yang dengan menggunakan teknik sampling jenuh, teknik penentuan sampel semua anggota populasi digunakan sebagai sampel (Sugiono, 2017:85). Pemilihan informan dipilih secara sengaja berdasarkan kriteria yang telah di tentukan dan menggunakan beberapa orang lain sebagai key informan, dalam penelitian ini adalah Seketaris Desa Sumber Harapan, Pendamping PKH Sulor Medan, dan Dinas Sosial (Koordinator Kabupaten PKH).

b. Data Sekunder

Data sekunder diperoleh dari kepustakaan, studi dokumentasi atau dari laporan penelitian terdahulu sehingga dalam penelitian ini dapat di peroleh melalui catatan-catatan, arsip, dan dokumen-dokumen lain yang dapat di gunakan sebagai informasi pendukung dalam analisis data primer (Kaelan, Ms, 2005:58). Data sekunder dalam penelitian ini berasal dari data 
Kantor Kepala Desa Sumber Harapan (data yang diperoleh berupa profil Desa Sumber Harapan), Badan Pusat Statistika (data yang diperoleh berupa data jumlah kemiskinanan di Kabupaten Sambas dan Jumlah Kemiskinana di Indonesia), dan Dinas Sosial.

\section{PEMBAHASAN}

A. Kondisi Masyarakat Desa Sumber Harapan

Dusun Solor Medan adalah salah satu dusun yang terletak Desa Sumber Harapan Kecamatan Sambas. Desa Sumber Harapan merupakan salah satu desa yang terdapat di Kecamatan Sambas. Desa ini memiliki luas $22,56 \mathrm{~km}^{2}(9,15 \%$ dari wilayah Kecamatan Sambas) dan merupakan desa terluas ke-7 dari 18 desa yang ada di Kecamatan Sambas.

Kondisi masyarakat Desa Sumber Harapan berdasarkan kondisi ekonomi masyarakat, pendidikan dan kesehatan bahwa untuk ekonomi masyarakat Desa Sumber Harapan menunjukan jumlah terbanyak pekerja penuh yaitu sebesar 1433 jiwa sedangkan untuk yang terendah yaitu kondisi jumlah ibu rumah tangga sebesar 497 jiwa.

Jumlah Tingkat pendidikan di Desa Sumber Harapan masyarakat dengan tingkatan tertinggi pendidkan adalah tamatan SD yang berjumlah 1198 sedangkan tingkatan paling sedikit iyalah S-1 sebanyak 52 orang. Untuk data kondisi kesehatan masyarakat desa Sumber Harapan mempunyai 1 buah puskesmas, bidan desa 1 orang, dan dengan balita sebanyak 291 anak sedangkan balita gizi buruk dan rumah tangga menggunakan air bersih atau pipa tangga iyalah tidak ada, dan rumah tangga yang menggunakan air bersih sebanyak 650 orang.

\section{B. Sejarah Program Keluarga Harapan Desa Sumber Harapan}

Kabupaten Sambas ditetapkan pertama kali sebagai lokasi pengembangan pelaksanaan PKH pada tahun 2013 berdasarkan Surat Direktur Jenderal Perlindungan dan Jaminan Sosial Kementerian Sosial RI nomor: 96/LJS.JS/03/2013 tanggal 8 Maret 2013. Alokasi calon peserta sebanyak 6.084 KSM (Keluarga Sangat Miskin) yang tersebar di 13 kecamatan. Seluruh data calon peserta tersebut harus dilakukan validasi (pencocokan data) sebelum ditetapkan sebagai peserta PKH. Untuk mengawal pelaksanaan PKH di lapangan Kementerian Sosial RI mengangkat tenaga pelaksana PKH yang ditempatkan di Kabupaten Sambas sebanyak 24 orang pendamping dan 1 orang operator.

Kegiatan validasi yang dilakukan oleh Pendamping $\mathrm{PKH}$ diawali dengan pertemuan awal (sosialisasi) dan dilanjutkan dengan validasi. Sebelum pelaksanaan pertemuan awal dan validasi, pendamping menyebarkan SUPA (Surat Undangan Pertemuan Awal) dan berkoordinasi dengan aparat Kecamatan dan Desa setempat.

Seluruh calon peserta PKH yang hadir diberikan penjelasan mengenai tujuan dan ketentuan $\mathrm{PKH}$, selanjutnya dilaksanakan validasi untuk melakukan pencocokan data antara yang tercetak di formulir validasi dan kenyataan di lapangan serta pemutakhiran data calon peserta $\mathrm{PKH}$. Apabila terdapat calon peserta $\mathrm{PKH} / \mathrm{KSM}$ terpilih yang tidak hadir dalam pertemuan tersebut, maka Pendamping berkewajiban melakukan home visit 
untuk menemui KSM tersebut setelah pertemuan awal dan melakukan proses validasi sebagaimana mestinya.

Setelah dilakukan validasi oleh Pendamping PKH di Kabupaten Sambas pada tahun 2013 dan ditetapkan oleh Direktur Jaminan Sosial Kementerian Sosial RI, maka diperoleh peserta eligible (memenuhi syarat) sebanyak 4.956 KSM dengan total bantuan sebesar Rp 3.385.425.000. Launching perdana penyaluran dana bantuan PKH kepada peserta PKH dilaksanakan pada tanggal 16 Januari 2014 bertempat di halaman kantor Dinas Sosial, Tenaga Kerja dan Transmigrasi Kabupaten Sambas oleh Bupati Sambas (Ibu dr. Hj. Juliarti Alwi, MPH). Saat itu penyaluran bantuan PKH masih dibayarkan melalui PT. Pos Indonesia.

Menindaklanjuti perluasan kepesertaan PKH yang direncanakan oleh Kementerian Sosial RI pada tahun 2014, maka Dinas Sosial, Tenaga Kerja dan Transmigrasi Kab. Sambas mengusulkan perluasan kepesertaan $\mathrm{PKH}$ pada 6 kecamatan lainnya, dan usulan tersebut disetujui oleh Kementerian Sosial RI dengan alokasi calon peserta sebanyak 1.134 Keluarga Sangat Miskin (KSM) dan penambahan tenaga Pendamping sebanyak 7 orang. Setelah dilakukan validasi oleh pendamping PKH terhadap calon peserta PKH dan hasilnya ditetapkan oleh Direktur Jaminan Sosial Kementerian Sosial RI pada tahun 2014, maka diperoleh peserta PKH eligible untuk pengembangan atau penambahan peserta pada tahun 2014 yang tersebar pada 6 kecamatan sebanyak $1.023 \mathrm{KSM}$ dengan total bantuan sebesar Rp 459.320.000.

Dengan demikian, maka pada tahun 2014 seluruh kecamatan (19 kecamatan) di Kabupaten Sambas telah menjadi lokasi pelaksanaan PKH, dengan jumlah peserta $6.211 \mathrm{KSM}$ (setelah 4 tahap pemutakhiran data) serta tenaga pelaksana PKH sebanyak 31 orang Pendamping dan 1 orang Operator.

\section{Karekteristik Responden}

Pada bagian ini karekteristik responden yang akan dibahas yaitu dimulai dari usia, jenis pekerjaan dan karekteristik masyaratak yang mendapatkan bantuan PKH. Hal ini bertujuan untuk mendapatkan informasi yang sesuai dengan pokok masalah yang ingin peneliti teliti. Penelitian ini dilakukan di Dusun Solor Medan dengan jumlah responden 37 orang.

Berdasarkan dari hasil wawancara diketahui bahwa umur responden yang berusia 22-27 tahun berjumlah 1 orang. Responden dengan umur 28-34 berjumlah 3 orang untuk responden dengan umum 3541 berjumlah 12 orang, responden dengan usia 42-48 berjumlah 6 orang, responden dengna umur 49-55 berjumlah 9 orang dan responden dengan umur 56-62 berjumlah 6 orang sekitar 22 sampai 59 tahun.

Jenis pekerjaan menunjukan bahwa responden yang bekerja sebagi Ibu Rumah Tangga berjumlah 33 orang sedangkan responden yang bekerja sebagai Pedagang berjumlah 2 orang dan responden yang berkerja sebagai penenun juga berjumlah 2 orang dengan jumlah pendapatan yaitu $\mathrm{Rp}$ 600.000 - Rp 1.000 .000 perbulan.

Sedangkan karekteristik responden dilihat dari masyarakat yang 
mendapatkan bantuan PKH bahwa responden yang memiliki dari keseluruan yaitu berjumlah 37 responden terdapat 63 orang keluarga dalam komponen pendidikan, sedangkan bayi berjumlah 3 orang dan balita berjumlah 10 orang sedangkan untuk lansia dan ibu hamil tidak ada.

D. Tingkat Efektivitas Program Keluarga Harapan (PKH) Dalam Pengentasan Kemiskinan Di Desa Sumber Harapan Dusun Solor Medan

Berdasarkan hasil wawancara Program Keluarga Harapan di dusun Solor Medan ini memfokuskan kedua komponen yaitu pendidikan dan kesehatan. Berikut ini peneliti akan menguraikan hasil temuan di lapangan efektivitas PKH berdasarkan tiga indikator efektivitas PKH yaitu input, proses dan output dapat dilihat dari table berikut ini:

Tabel 5

Data tingkat Jumlah Efektivitas

\begin{tabular}{|c|c|c|c|}
\hline \multirow{2}{*}{ Efektivitas } & Input & Proses & Output \\
\cline { 2 - 4 } & $100 \%$ & $100 \%$ & $100 \%$ \\
\hline
\end{tabular}

Sumber : data diolah dari hasil sebaran kuesioner

Tabel 3 diatas hasil dari kuesioner menunjukan bahawa dari 37 peserta PKH menjawab Ya atau 100\% untuk pertanyaan indikator input yang berjumlah 8 pertanyaan untuk setiap peserta PKH. Untuk indikator proses semua peserta PKH dari 7 pertanyaan semua menjawab Ya sebanyak 5 pertanyaan dan Tidak untuk 2 pertanyaan atau sekitar $100 \%$, sedangkan untuk indikator output yang berjumlah 5 pertanyaan semua peserta PKH yang berjumlah 37 orang juga menjawab Ya atau 100\%.

a. Indikator input,

Ketetapan sasaran program sasaran PKH adalah rumah tangga sangat miskin. Dari hasil penyebaraan kuesioner, pernyataan ibu Susi bahwa peserta PKH dikumpulkan dan diberi arahan oleh ketua PKH untuk mendengarkan sosialisasi dan informasi dari pihak PKH yang didampingi oleh ibu Evi selaku pendamping PKH.

Untuk status penguasaan bangunan tempat tinggal yang ditempati oleh peserta PKH ; dari pertanyaan sebanyak 37 orang juga menjawab Ya bahwa bangunan yang yang dimiliki merupakan milik mereka. Sebagaimana pernyataan ibu Aminah pada mulanya tempat tinggal yang ditinggali merupakan milik orang lain dengan kata lain ibu Aminah menyewa, namun setelah mendapatkan bantua PKH ibu Aminah bisa menabung penghasilannya dan dengan tabungananya dapat membeli dan membuat tempat tinggalnya berubah status menjadi milik ibu Aminah.

Selanjutnya pertanyaan status lahan tempat tinggal yang ditempati milik sendiri atau bukan; dari pertanyaan tersebut semua responden menjawab Ya. Bahwa pada mulanya tanah atau lahan yang ditinggali sebenarnya milik orang lain namun kemudian dibeli oleh ibu Rini dan beralih status menjadi milik sendiri. 
Pertanyaan Keadaan jenis lantai, dinding dan atap saudar/i sudah lebih baik setelah mendapatkan bantuan $\mathrm{PKH}$; dari pertanyaan tersebut semua responden yang berjumlah 37 orang menjawab Ya. Sebelumnya masih menggunakan lantai, dinding kayu dan atap daun nama lama-kelamaan apalagi setelah mendapatkan bantuan $\mathrm{PKH}$ yang tadinya masih menggunkan lantai dan dinding kayu sekarang sudah berubah mejadi semen dan menggunkan atap dari seng.

Selanjutnya pertanyaan keliam mengenai sumber air minum dan cara membeli air minum oleh responden sudah lebih baik setelah mendapatkan bantua $\mathrm{PKH}$; dari pertanyaan kelima ini juga semua responden menjawa Ya. Pertanyaan keenam yaitu berhubungan dengan sumber daya penerangan sudah lebih baik setelah mendapatkan bantua $\mathrm{PKH}$; dari pertanyaan tersebut semua peserta PKH menjawan Ya. Penerangan yang digunakan sudah baik yaitu menggunkan penerangan dari listrik.

Untuk pertanyaan ketujuh yaitu mengenai bahan bakar utama yang digunakan untuk memasak; dari pertanyaan tersebut responden yang berjumlah sebanyak 37 orang menjawab Ya. Pertanyaan yang terakhir atau Pertanyaan kedelapan yaitu mengenai fasilitas toilet sudah lebih baik atau tidak; dari pertanyaan terakhir ini responden sebanyak 37 orang juga menjawab Ya. Sekarang untuk faslitas toilet sudah baik yang dulunya tidak punya toilet tetapi sekarang sudah dan tidak lagi sembarangan.

b.Indikator Proses,

persepsi KPM terhadap pelaksanaan program Dari hasil penyebaran kuesioner di dusun solor medan dengan pertanyaan yang diajukan sebanyak 7 pertanyaan untuk indikator proses dapat diketahui bahwa sebanayak 37 peserta $\mathrm{PKH}$ menjawab Ya untuk 5 pertanyaan dan 2 pertanyaan semua peserta PKH peserta menjawab Tidak. Seperti berikut ini:

Pertanyaan pertama mengenai pendamping $\mathrm{PKH}$ dalam menjelaskan tugasnya dan memimbing para peserta $\mathrm{PKH}$; semua peserta sebanyak 37 orang menjawab Ya. Sebagaimana yang diungkapkan bahwa dalam melakukan tugasnya ibu Evi selaku pendamping PKH sudah baik dalam menjalankan tugasnya.

Pertanyaan kedua yaitu berhubungan dengan mengadakan pertemuan rutin oleh peserta $\mathrm{PKH}$; dari pertanyaan tersebut semua responden menjawab Ya. Sebagaimana hasil wawancara dari salah satu responden dalam pertemuan rutin dilakukan sebanyak satu kali dalam satu bulan yang dilaksanakan dikediaman ketua PKH kelompok mereka dan didampingi oleh pendamping PKH yaitu ibu Evi. Dalam pertemuan rutin wajib diikuti oleh peserta $\mathrm{PKH}$, apabila peserta $\mathrm{PKH}$ ada yang tidak mengikuti pertemuan rutin lebih dari tiga kali maka akan ditangguhkan atau dicabut bantuannya.

Selanjutnya Pertanyaan ketiga dan keempat yaitu tentang syaratsyarat dari PKH; dari pertanyaan tersebut semua peserta menjawab Ya, sebagaimana wawancara kepada ibu Mawarni mereka sebagai peserta 
PKH sudah memenuhi syarat-syarat dan tidak keberatan dengan syarat dari PKH tersebut.

Pertanyaan kelima mengenai tahap pencairan dana dilakukan; semua responden menjawan Ya, sebagaimana hasil wawancara salah satu responden yaitu ibu Inur mengatakan pencairan dana yang diterima tepat waktu dengan empat tahapan dan dalam tiga bulan sekali pengambilan dana selama satu tahun.

Untuk pertanyaan keenam apakah dana $\mathrm{PKH}$ yang diterima sesuai dengan jumlah yang ditetapkan; dari pertanyaan tersebut semua responden juga menjawab Ya, bahwa peserta telah menerima jumlah dana yang sesuai dengan komponen yang mereka miliki dan yang sudah ditentukan oleh pihak PKH itu sendiri.

Terakhir pertanyaan ketujuh mengenai pemotongan dana saat penerimaan dana dari pihak tertentu; dari pertanyaan tersebut semau responden yang berjumlah 37 orang menjawab Tidak, dari hasil wawancara kepada salah satu responden yaitu ibu Aina menyatakan saat penerimaan tidak terdapat pemotongan dana dari pihak manapun dana yang telah diterima semuanya milik penerima $\mathrm{PKH}$, hanya saja saat penarikan peserta PKH membayar admin karena telah menggunakan jasanya untuk penarikan jumlah uang yang akan diambil.

c. Indikator Output,

Tercapainya tujuan PKH meningkatnya akses KPM terhadap layanan kesehatan dan pendidikan. Dari hasil penyebaran kuesioner di dusun solor medan dengan pertanyaan yang diajukan sebanyak 5 pertanyaan untuk indikator output dapat diketahui bahwa sebanayak 37 peserta $\mathrm{PKH}$ menjawab Ya dan nol peserta atau tidak ada peserta uang menjawab menjawab Tidak.

Pertanyaan pertama berhubungan dengan sosialisasi yang diberikan dapat memahami tujuan, kewajiban, serta hak-hak sebagai peserta PKH; dari pertanyaan tersebut semua responden menjawab Ya. Dalam proses sosialiasasi oleh pihak $\mathrm{PKH}$ memberikan pemahaman kepada peserta penerima bantuan PKH seperti tujuan dari PKH itu sendiri yaitu untuk mengurangi beban dan untuk menambah pendapatan kepada keluarga penerima bantuan ini.

Kedua pertanyaan mengenai dana yang di terima digunakan untuk kebutuhan pendidikan,kesehatan, dan pemenuhan kebutuhan bagi lansia dan disabilitas berat; dari pertanyaan tersebut dari 37 responden juga menjawab Ya. Berdasarkan hail wawancara salah satu responden yaitu ibu Yati menyatakan dana yang diterima digunakan untuk kebutuhan membayar bulananan sekolah anak dan selain itu mengikuti kegiatan posyandu yaitu selama satu kali dalam satu bulan."

Untuk pertanyaan ketiga tentang adanya $\mathrm{PKH}$ kualitas kebutuhan pendidikan, kesehatan dan pemenuhan kebuuhan bagi lansia dan disabilitas berat meningkat; dari pertanyaan tersebut semua responden menjawab Ya, dari pernyataan tersebut bahwa setelah mendapatan bantuan $\mathrm{PKH}$ kesehatan dan pendidikan anak meningkat dan saat selesai sekolah kembali di sekolahkan lagi kejenjang 
berikutnya agar tidak putus sekolah dan kesehatan juga meningkat degan periksa ke puskesmas biasa seminggu sekali.

Pertanyaan keempat yaitu mengenai dana yang di terima gunakan untuk kebutuhan lain selain pendidikan kesehatan dan pemenuhan kebutuhan bagi lansia dan disabilitas berat; dari pertanyaan tersebut semua responden juga menjawab Ya, berdasarkan hasil wawancara kepada salah satu responden bernama ibu Halida mengatakan yang diterimanya boleh juga digunakan untuk keperluan lain tetapi setelah memenuhi keperluan pendidikan dan kesehatan, yang mana dana digunakan untuk keperluan sehari-hari untuk memenuhi kebutuhan pokok seperti kebutuhan untuk makan seharihari.

Berdasarkan ketiga indikator tersebut yaitu indikator input, proses dan output dapat diketahui bahwa sebanayak 37 peserta $\mathrm{PKH}$ menjawab Ya atau 100\% untuk indikator input, dan untuk indikator proses sebanyak 5 pertanyaan semua peserta menjawab Ya atau 100\% Ya sedangkan untuk indikator output semua responden menjawab Ya atau $100 \%$.

\section{E. Perubahan Kesejahteraan Masyarakat dengan adanya Program Keluarga Harapan di Desa Sumber Harapan Dusun Solor Medan}

Badan Koordinasi Keluarga Berencana (BKKBN) memberikan beberapa indikatornya sebagai acuan dalam penentuan keluarga sejahtera yang terdiri dari 20 indikator. Berdasarkan hasil wawancara dan jawaban kuesioner pada peserta $\mathrm{PKH}$ yang berjumlah 37 responden menunjukan bahwa terdapat 20 keluarga sejahtera berada ditahapan keluarga sejahtera I (KS I), sedangkan 15 keluarga sejahtera yang berada ditahapan keluarga sejahtera II dan terdapat 2 keluarga sejahtera yang berada ditahapan keluarga sejahtera III plus.

Seperti yang diungkapkan oleh salah satu peserta $\mathrm{PKH}$ yang bernama ibu Mahdila yang termasuk ketahap keluarga sejahtera I mewakili responenden lain menyatakan bahwa dengan adanya bantuan PKH ini membuat perubahan seperti makan sehari-hari yang lebih dari dua kali dalam sehari dengan mengkonsumsi ikan atau telur kurang dari seminggu sekali dan juga membeli baju baru walaupun setahun sekali dan juga pendidikan anak yang sudah disekolahkan.

Selanjutnya Responden yang tergolong kedalam tahap keluarga sejahtera II berjumlah 15 orang tahap keluarga sejahtera II yaitu keluarga yang mampu memenuhi 6 (enam) indikator tahapan KS I, tetapi tidak memenuhi salah satu dari 5 (lima) indikator keluarga sejahtera III (KS III), atau indikator pengembangan (developmental mneeds) dari keluarga.

Setelah mendapatkan bantuan ini kesehatan keluarga ibu Ningsih dalam keadaan sehat dalam tiga bulan terakhir dan untuk penghasilan juga ibu Ningsih bisa menyisihkan uangnya untuk ditabung. Selanjutnya untuk responden yang tergolong kedalam tahap keluarga sejahtera III plus berjumlah 2 orang dari 37 responden yaitu keluarga yang mampu memenuhi keseluruhan dari 6 (enam) indikator tahapan KS I, 8 (delapan) indikator KS II, 5 (lima) indi kator KS III, serta 2 (dua) indikator tahapan KS 
III.

Bantuan PKH ini sudah lebih baik untuk kesejahteranya seperti bidang kesehatan bahwa dalam tiga bulan terakhir keluarganya dalam keadaan sehat. Untuk pendidikan juga sudah baik yang mana anak mereka yang berusia 7-15 tahun sudah bisa sekolah., status tempat tinggal mereka juga sudah berstatus milik sendiri yang mana pada awalnya hanyalah sebagai penyewa, sumbangan materiil juga diberikan setiap satu kali dalam seminggu dan juga mengikuti kegiatan masyarakat seperti pengajian dan ikut kegiatan PKK sudah berjalan cukup baik.

\section{F. Tingkat Efektivitas Program Keluarga Harapan (PKH) Dalam Pengentasan Kemiskinan Di Desa Sumber Harapan Dusun Solor Medan}

Untuk Mengetahui tingkat efektivitas Program Keluarga Harapan (PKH) dalam pengentasan kemiskinan di Dusun Solor Medan, perolehan data melalui penyebaran kuesioner sebanyak 8 pertanyaan untuk indikator input, 7 pertanyaan untuk indikator prosses dan 5 pertanyaan untuk indikator output untuk 37 peserta PKH. Hasil sebaran kuesioner didapatkan hasil berikut ini:

a. Indikator Input, Ketepatan sasaran program: sasaran PKH adalah RTSM (Rumah Tangga Sangat Miskin). Untuk mengetahui efektivitas Program Keluarga Harapan di Dusun Solor Medan, perolehan data melalui penyebaran angket sebanyak 8 pertanyaan untuk 37 peserta $\mathrm{PKH}$ memenuhi $100 \%$ dari indikator input. Hal ini menjelaskan bahwa semua keluarga penerima manfaat telah memenuhi indikator input dan pemerintah tepat sasaran dalam memilih Keluarga Penerima Manfaat untuk bantuan Program Keluarga Harapan $(\mathrm{PKH})$. Hal ini Karen pemerintah melakukan sosilisasi dan memberikan informasi melalui petugas $\mathrm{PKH}$ yang telah di tentukan, agar peserta mengetahui semua hal yang berhubungan dengan Program Keluarga Harapan ini.

b. Indikator Proses, persepsi KPM terhadap pelaksanaan program Dari hasil penyebaran kuesioner di dusun solor medan dengan pertanyaan yang diajukan sebanyak 7 pertanyaan untuk indikator proses dari 37 responden memenuhi $100 \%$ dari indikator proses. Hal ini juga menjelaskan bahwa ketepatan sasaran pemerintah dalam memilih Keluarga Penerima Manfaat untuk bantuan Program Keluarga Harapan (PKH). Hal ini dapat dilihat dari peserta PKH yang telah memenuhi hak dan kewajiban dan mengikuti semua aturan yang telah ditetapkan sebagai Peserta $\mathrm{PKH}$, dengan pertemuan rutin yang telah diadakan oleh pendamping $\mathrm{PKH}$ dan wajib diikuti oleh peserta $\mathrm{PKH}$.

c. Indikator Output, Tercapainya tujuan PKH meningkatnya akses KPM terhadap layanan kesehatan dan pendidikan. Dari hasil penyebaran kuesioner di dusun solor medan dengan pertanyaan yang diajukan sebanyak 5 pertanyaan memenuhi 100\% dari indikator Output. Hal ini dapat dilihat dari dana bantuan yang telah digunakan sesuai dengan kebutuhan dari komponen yang telah diterima dan ditentuakan, dan telah meningkatkan kebutuhan pendidikan, kesehatan dan kebutuhan bagi lansia dan disabilitas berat. 


\section{G. Perubahan Kesejahteraan Masyarakat dengan adanya Program Keluarga Harapan di Dusun Solor Medan Desa Sumber Harapan}

Dari standar BKKBN, dikatakan sejahtera apabila memenuhi 20 indikator dan termasuk ke tahapan yang ditentukan BKKBN. Hasil wawancara dan kuesioner dengan 19 pertanyaan yang berdasarkan indikator dari BKKBN terdapat 20 keluarga yang berada ditahapan sejahtera I (KS I), sebanyak 15 keluarga berada ditahapan sejahtera II (KS II) dan sebanyak 2 keluarga berada ditahapan keluarga sejahtera III Plus. Hal ini dapat dilihat dari indikator-indikator yang telah terpenuhi oleh 37 responden terdapat perubahan yang terjadi dari kebutuhan pokok maupun tempat kondisi tempat tinggal.

\section{PENUTUP}

Berdasarkan hasil penelitian mengenai analisis efektivitas program keluarga (PKH) dalam pengentasan kemiskinan di Dusun solor medan dapat disimpulkan sebagai berikut:

1. Tingkat Efektivitas Program Keluarga Harapan (PKH) Dalam Pengentasan Kemiskinan Di Desa Sumber Harapan Dusun Solor Medan yang berdasarkan tiga indikator yaitu indiktor input, poses dan output hasil penelitian membuktikan bahwa Program Keluarga Harapan (PKH) Di Dusun Solor Medan dengan jumlah peserta penerima berjumlah 37 orang sangat efektif.

2. Perubahan Kesejahteraan Masyarakat dengan adanya Program Keluarga Harapan di Desa Sumber Harapan berdasarkan standar indikator BKKBN, dari 19 indikator yang menentukan tahapan kesejahteraan yang terdiri dari 5 tahapan dan hasil penelitian membuktikan bahwa dengan Program Keluarga Harapan (PKH) Di Dusun Solor Medan tingkat ke sejahteraan penerima PKH meningkat yaitu dari 37 peserta Terdapat 20 keluarga sejahtera berada ditahapan keluarga sejahtera I (KS I) yaitu keluarga yang mampu memenuhi 5 (lima) indikator tahapan KS I, tetapi tidak memenuhi salah satu dari 8 indikator keluarga sejahtera II atau indikator kebutuhan psikologis, Sedangkan 15 keluarga sejahtera yang berada ditahapan keluarga sejahtera II yaitu kelurga yang mampu memenuhi 5 (lima) indikator tahapan KS I, tetapi tidak mmemenuhi salah satu dari 5 (lima) indikator KS III atau indikator pengembangan (developmental needs) dari keluarga. Dan terdapat 2 kelurga sejahtera yang berada ditahapan keluarga sejahtera III plus yaitu keluarga yang mampu memenuhi keseluruhan dari 5 indikator tahapan KS I, 8 indikaator KS II, 5 indikator KS III serta 2 indikator tahapan KS III. 


\section{DAFTAR PUSTAKA}

Amalia, Euis. (2009). Keadilan Ditributif dalam Ekonomi Islam, Jakarta: PT RajaGrafindo Persada.

Badan Pusat Statistik, "jumlah Penduduk Indonesia." http://www.bps.go.id), diakses tanggal 30 Nopember 2020.

Direktorat Jaminan Sosial Keluarga,"Pedoman Pelaksanaan PKH Tahun 2019, https://pkh.kemensos.go.id, diakses tanggal 5 September 2020.

Kaelan, M.s. (2005). Metodologi Penelitian Kualitatif Bidang Filsafat.Yogyakarta: Paradigma.

Kartika Nih Ayu, dkk, "Pengukuran Tingkat Efektifitas dan Efesiensi Sistem E-Risearach STIKOM Bali", Konferensi Nasional Sistem dan Informatika 2015, Vol. 11, No 2 2017, Jurnal Sistem dan Informatika, http://studyblibid.com.

Kementrian Sosial, "Undang-undang Nomor 11 Tahun 2009 tentang Kesejahteraan Sosial",(online) (https//www.kemsos.go.id/unduh/UUkesos-No1 12009.pdf), diakses tanggal 15 November 2020.

Mahdi, Adnan, dan Mujahidin. (2014). Panduan Penelitian Praktis untuk Menyusun Skripsi, Tesis Disertasi. Bandung: Alfabeta.

Prichatin Asti, "Efektivitas Program Keluarga Harapan (Pkh) Dalam Upaya Meningkatkan Kesejahteraan Keluarga."Skripsi pada IAIN Purwokorto Tahun 2019.

Rahajo, Budi "Jumlah Penduduk Miskin RI. (on-line) (https://cnnindonesia.com), diakse tanggal 30 Nopember 2020.

Sugiyono. (2017). Metode Penelitian Bisnis. Bandung : Alfabeta.

Sugiono. (2017. Metode Penelitian Kualitatif untuk penelitian yang bersifat eksplorasi, enterpretif, interaktif, dan kontruktif, Afabeta, Bandung,

Sugiyono. (2017). Metode Penelitian kuantitatif, Kualitatif dan R\&D. Bandung : Alfabeta.

Sumber

Harapan

Sambas, https://id.wikipedia.org/wiki/Sumber_Harapan,_Sambas,_Sambas, diakases tanggal 10 Agustus 2020. 
Tim Nasional Percepatan Penanggulangan Kemiskinan, Panduan Pemantuan Program

TNP2K, "Program Penanggulangan Kemiskinan",(On-line) (http://www. tnp2k.go.id/id/ program/sekilas/, ), diakses tanggal 15 November 2020

Wawancara Ketua PKH Bu Evi Sumber Harapan Kecamatan Sambas, pada Selasa, 15 Januari 2019. 